\title{
Correlação entre o Raciocínio Lógico e o Raciocínio Matemático em Crianças Escolarizadas
}

\section{Correlation between Logical Reasoning and Mathematical Reasoning in School Children}

\author{
Simone de Oliveira Andrade Silva* \\ ORCID iD 0000-0002-5001-7690 \\ Sérgio Vasconcelos de Luna** \\ ORCID iD 0000-0002-3162-8859
}

\begin{abstract}
Resumo
O objetivo deste estudo foi identificar possíveis relações entre problemas que envolvem raciocínios lógico e matemático no desempenho de 26 crianças, distribuídas em dois grupos (fortes e fracos, classificados inicialmente pelo seu desempenho em matemática - aritmética). O campo de pesquisa foi uma escola municipal de Ensino fundamental de São Paulo. Aplicou-se um instrumento composto de cinco conjuntos de problemas (dois avaliaram o raciocínio matemático e três avaliaram o raciocínio lógico verbal). Os resultados sugerem que há correlação entre o raciocínio lógico e o raciocínio matemático, pois todas as variáveis apresentaram uma correlação de moderada a forte com o teste classificatório de Matemática, indicada pelo valor de $r$ no Teste de Correlação Pearson-r. Todas as correlações foram positivas e significativas, mesmo para os problemas-controle. Diante de dificuldades para resolução de determinados problemas, observou-se forte controle incorreto da presença/ausência de número nos problemas matemáticos e forte controle incorreto do enunciado nos problemas que envolviam lógica.
\end{abstract}

Palavras-Chave: Educação. Psicologia. Resolução de Problemas Lógicos. Resolução de Problemas Matemáticos.

\begin{abstract}
The aim of this study was to identify possible relationships between problems involving logical and mathematical reasoning in the performance of 26 children, divided into two groups (strong and weak, initially sorted by their performance in mathematics - arithmetic). The research field was a municipal elementary school in São Paulo. We applied an instrument composed of five sets of problems (two evaluated mathematical reasoning and three evaluated logical reasoning). The results suggest that there is a correlation between logical reasoning and mathematical reasoning, since all variables showed a moderate to strong correlation with the

\footnotetext{
* Titulação Doutora e mestra em Educação; Psicologia da Educação pela Pontifícia Universidade Católica de São Paulo (PUC-SP). Pós-Doutoranda no mesmo Programa (PUC-SP). Endereço para correspondência: Rua Ministro Godoy, 969, 4. ${ }^{\circ}$ andar - sala 4E-07 - CEP 05015-901, Perdizes, São Paulo/SP. E-mail: mone.oliveira.andrade@gmail.com.

** Doutor em Psicologia, pela Universidade Católica de São Paulo (USP) e mestre em Educational Psychology, pela University Massachusetts System. Professor titular da Pontifícia Universidade Católica de São Paulo (PUCSP), nos programas de pós-graduação em Educação: Psicologia da Educação e Psicologia Experimental. Endereço para correspondência: Rua Ministro Godoy, 969, 4. ${ }^{\circ}$ andar - sala 4E-07 - CEP 05015-901, Perdizes, São Paulo/SP. E-mail: svluna@gmail.com
} 
mathematical classification test, indicated by the value of $\mathrm{r}$ in the Pearson- $r$ Correlation Test. All correlations were positive and significant, even for control problems. Faced with difficulties in solving certain problems, there was strong incorrect control of the presence/absence of numbers in mathematical problems and strong incorrect control of the statement in problems involving logic.

Keywords: Reasoning. Education. Psychology. Solving Logical Problems. Solving Mathematical Problems.

\section{Introdução ${ }^{1}$}

O raciocínio lógico e o raciocínio matemático e suas implicações na aprendizagem são temas recorrentes na literatura acadêmica (KRUTETSKII, 1976; MEIRA; DIAS; SPINILLO, 1993; BRITO; FINI; GARCIA, 1994; RUSSEL; 1999; RODRIGUES; DIAS; ROAZZI, 2002; TINELI, 2006; NUNES et al., 2007; LUNA; MARINOTTI, 2012; NUNES et al., 2012). Contudo, poucos estudos têm se dedicado em analisar a relação entre ambos os raciocínios. Em 1976, Krutetskii "verificou que alunos com fraca capacidade para a matemática apresentavam, também, insuficiente desenvolvimento lógico-verbal de atividade intelectual" (BRITO; FINI; GARCIA, 1994, p. 37). Ele identificou que altas habilidades lógicas não garantiam bom desempenho matemático, mas que o indivíduo que possuía baixo nível do componente lógico-verbal tinha dificuldade de compreensão da Matemática (KRUTETSKII, 1976). É necessário enfatizar que os participantes estudados por Krutetskii eram altamente habilidosos, ou seja, pertenciam a um grupo de pessoas caracterizado como superdotados, diferentemente do grupo participante deste estudo. Entretanto, considerou-se importante apresentar seus estudos, por se tratar de referência para destacar a relação entre Matemática e lógica.

Nunes et al. (2007) identificaram a existência de uma relação causal entre lógica e desenvolvimento matemático em crianças no início da sua escolarização. Em outro estudo, Nunes et al. (2012) trouxeram mais dados para confirmar esses resultados, ao analisar os resultados de uma avaliação educacional em larga escala. Eles verificaram que o progresso das crianças em Matemática estava diretamente influenciado pelo seu desempenho em raciocínio matemático.

Interessados em investigar essa relação entre lógica e Matemática, Luna e Marinotti (2012, p. 13), investigaram a "identificação e explicitação de relações entre habilidades lógicas e habilidades matemáticas", no desempenho em problemas que envolviam lógica e em problemas matemáticos de crianças de 7 a 8 anos. Todavia, o instrumento pareceu inadequado

\footnotetext{
${ }^{1}$ Este estudo foi financionado pelo Conselho Nacional de Desenvolvimento Científico e Tecnológico - CNPq.
} 
para a faixa etária. Em uma replicação desta pesquisa, Kramm (2014) aplicou o instrumento em crianças de 8 a 9 anos e acrescentou análises estatísticas sobre as informações coletadas. Os resultados sugeriram haver forte relação entre lógica e Matemática, entretanto, também para esta faixa etária o instrumento não estava adequado, visto que a grande parte das dificuldades encontradas por eles versavam principalmente sobre falta de background.

Este estudo também é uma replicação sistemática da pesquisa de Luna e Marinotti (2012). Para verificar a relação entre o raciocínio matemático e o raciocínio lógico, a hipótese que orientou a pesquisa foi a seguinte: Há diferença entre os participantes com bom desempenho e com baixo desempenho em matemática (aritmética) no seu desempenho em problemas que envolvem lógica verbal e em problemas matemáticos.

\section{Método}

Nesse estudo, duas abordagens foram utilizadas: uma quantitativa e outra qualitativa. A escolha pela utilização de ambas está relacionada com o que se queria pesquisar, pois "as decisões metodológicas são pura decorrência do problema formulado" (LUNA, 1988). Diante disso, não se deve privilegiar uma e menosprezar outra abordagem, porque qualidade e quantidade devem caminhar juntas em uma pesquisa. A definição do problema é que vai direcionar o tipo de pesquisa, ao se distinguir seus aspectos específicos (ANDRÉ, 2013). O mais importante não é esta distinção, mas a produção de pesquisas científicas de qualidade.

Para a coleta dos dados, além da resposta de cada participante aos itens, foi incluído o inquérito, para garantir a captura do seu raciocínio e verificar se sua resposta resistiria aos confrontos propostos pela pesquisadora (ou, ao contrário, se isso faria com que ele mudasse sua resposta).

\subsection{Participantes e local}

Foram selecionados 26 participantes, de ambos os sexos, com idades entre 9 e 10 anos, matriculadas no $4 .^{\circ}$ ano do Ensino Fundamental de uma escola municipal de São Paulo. Eles foram, então, divididos em dois diferentes grupos, sendo: 13 considerados fracos no desempenho na atividade de Matemática e 13, fortes. Doravante, serão denominados de $F$ (os alunos que apresentaram bom desempenho) e $f$ (os que não apresentaram bom desempenho).

\footnotetext{
${ }^{2} \mathrm{O}$ projeto foi aprovado pelo Comitê de Ética sob n ${ }^{\circ}$ CAAE: 49601315.9.0000.5482.
} 
O procedimento para essa classificação o agrupamento foi a aplicação de um teste classificatório de Matemática (aritmética), da prova de matemática do SARESP (SÃO PAULO, 2014) relacionado aos conhecimentos sobre numeração e resolução de problemas. Os resultados desse teste foram apresentados às professoras para confirmar se o desempenho dos participantes era semelhante ao demonstrado por eles nas atividades cotidianas em sala. A consulta resultou em afirmação da similaridade nos desempenhos encontrados nas duas situações.

\subsection{Material}

$\mathrm{O}$ instrumento (60 itens, sendo: problemas matemáticos - 24 itens e problemas lógicos - 36 itens), foi aplicado e validando por pesquisadores de estudos anteriores (KRAMM, 2014; LUNA; MARINOTTI, 2012). Algumas pequenas alterações foram realizadas com relação à linguagem ou para evitar controles inadequados pelo enunciado que, no entanto, não feriram o objetivo proposto pelo instrumento inicialmente elaborado. Os problemas e sua natureza são indicados a seguir.

\subsubsection{Problemas que exigiam raciocínio matemático}

O raciocínio matemático é descrito como fundamental por autores para o desenvolvimento da aprendizagem matemática. Sua descrição difere na descrição dos autores, que salientam diferentes aspectos. Oliveira (2008, p. 3) descreve que raciocínio matemático é "um conjunto de processos mentais complexos através dos quais se obtêm novas proposições (conhecimento novo) a partir de proposições conhecidas ou assumidas (conhecimento prévio)". Já Russel (1999, p. 1) indicou que ele é “o que usamos para pensar sobre as propriedades de um determinado objeto matemático e desenvolver generalizações que se apliquem a toda a classe de objetos".

Neste estudo, utilizou-se a definição de Brito, Fini e Garcia (1994, p. 38), que destacaram que "compreensão da natureza do problema matemático e resolução do problema [...] é habitualmente denominado de raciocínio matemático [...]”. Essa pesquisa contou com os seguintes problemas que envolviam raciocínio matemático, num total de 24 :

- Variável Problemas Sem Número (ou nos quais o número era insuficiente para a resolução do item): a resposta deveria demonstrar o raciocínio usado, não sendo necessária realizar operações. Não era necessário que a criança falasse corretamente o nome da operação. 
Termos como "fazer conta de mais" ou "juntar tudo" eram aceitos como respostas corretas, desde que a justificativa demonstrasse sua compreensão correta da operação. O Quadro 1 apresenta exemplos dos itens e o que se esperava como resposta:

\begin{tabular}{|c|c|c|}
\hline $\mathbf{N}$ & Questão & Esperava-se que ele respondesse que... \\
\hline 1 & $\begin{array}{l}\text { Pedro emprestou algumas revistas de história para o seu primo. } \\
\text { Quando ele for lhe devolver, como poderá fazer para saber se o } \\
\text { número de revistas é o mesmo que ele emprestou? }\end{array}$ & $\begin{array}{l}\text {...era necessário contar as revistas que } \\
\text { foram devolvidas, para saber se todas } \\
\text { estavam lá. }\end{array}$ \\
\hline 2 & $\begin{array}{l}\text { Rodrigo acaba de ler um livro de História, outro de Geografia e } \\
\text { outro de Ciências. Se a mãe dele perguntar quantas páginas ele } \\
\text { leu, o que ele precisa fazer para saber responder? }\end{array}$ & $\begin{array}{l}\text {... era necessário somar o número de } \\
\text { páginas lidas dos três livros para } \\
\text { responder ao item. }\end{array}$ \\
\hline 3 & $\begin{array}{l}\text { Algumas amigas dividiram um pacote de biscoito. Cada uma } \\
\text { recebeu } 1 \text { biscoito. Como você pode fazer para descobrir quantos } \\
\text { biscoitos havia no pacote? }\end{array}$ & $\begin{array}{l}\text {... deveria somar quantas amigas } \\
\text { receberam o biscoito. }\end{array}$ \\
\hline
\end{tabular}

Quadro 1 - Itens da variável Sem Número e respostas esperadas Fonte: Elaborado pelos autores (2016).

- Variável Problemas Com e Sem Solução: esta variável continha 12 itens: cinco com solução (problemas-controle), nos quais operações matemáticas possibilitam alcançar um resultado; e sete sem solução, cujo raciocínio matemático indicaria a impossibilidade de se trabalhar sobre ele, ou seja, o participante deve perceber que eles são insolúveis. Incluiu-se dois tipos de itens para evitar que o participante discriminasse que todos seriam insolúveis e, com isto, respondesse mecanicamente aos subsequentes. Segue Quadro 2 com alguns dos itens e o que se esperava como resposta do participante.

\begin{tabular}{|c|c|c|}
\hline $\mathbf{N}$ & uestão & Esperava-se que ele respondesse que era... \\
\hline \multicolumn{3}{|c|}{ Sem Solução } \\
\hline 1 & $\begin{array}{l}\text { A avó de João abriu uma caixa cheia de bombons. Deu } \\
3 \text { para sua irmã, } 2 \text { para seu irmão e } 5 \text { para ele. Quantos } \\
\text { bombons ainda têm na caixa? }\end{array}$ & $\begin{array}{l}\text {... impossível responder, pois não se sabe quantos } \\
\text { bombons havia na caixa, quando a vovó a abriu. }\end{array}$ \\
\hline 2 & $\begin{array}{l}\text { Paulo tem } 3 \text { carrinhos e } 4 \text { aviões. Quantos soldadinhos } \\
\text { ele tem? }\end{array}$ & $\begin{array}{l}\text {.. impossível re } \\
\text { dadas não são suf }\end{array}$ \\
\hline 3 & $\begin{array}{l}\text { A professora disse para Marina que seu peso é } 15 \\
\text { quilos e do seu irmão é } 17 \text { quilos. Qual é o peso de seu } \\
\text { amigo João? }\end{array}$ & $\begin{array}{l}\text {... impossível responder, pois as informações } \\
\text { dadas não são suficientes para responder ao item. }\end{array}$ \\
\hline \multicolumn{3}{|c|}{ Com solução } \\
\hline 4 & $\begin{array}{l}\text { O pai de Júlia tinha } 27 \text { galinhas na sua chácara. Uma } \\
\text { doença matou } 27 \text { delas. Com quantas galinhas vivas } \\
\text { ficou o pai de Júlia? }\end{array}$ & $\begin{array}{l}\text {... necessário subtrair do total de galinhas quantas } \\
\text { galinhas morreram. }\end{array}$ \\
\hline 5 & $\begin{array}{l}19 \text { páginas do livro. Só faltam } 28 \text { pág } \\
\text { le ler o livro. Quantas páginas têm o li }\end{array}$ & $\begin{array}{l}\text {... necessário somar o que já havia sido lido com } \\
\text { o restante de páginas que ainda faltavam ser } \\
\text { lidas. }\end{array}$ \\
\hline
\end{tabular}

Quadro 2 - Itens da variável Com e Sem Solução e respostas esperadas Fonte: Elaborado pelos autores (2016).

\subsubsection{Problemas que exigiam raciocínio lógico}

A Lógica Formal ou Clássica de Aristóteles que se importa estritamente com a forma do argumento e não com o seu conteúdo (MACHADO; CUNHA, 2005), não foi empregada nesse estudo. Aqui, foi utilizada a Lógica Não Clássica ou Argumentativa, que se aproxima 
mais da linguagem cotidiana, por utilizar a linguagem como instrumento para exercitar a capacidade de argumentação.

Nos problemas lógicos, três variáveis foram incluídas: com Inversão Causal, com Inversão Temporal e Gerais. Os itens foram divididos em: possíveis (utilizados como problemas-controle) e impossíveis, para que o participante não ficasse controlado por um modelo único. Inicialmente, o participante era informado sobre a existência dos dois tipos.

- Variável Problemas com Inversão Causal - IC:

Falácias causais do tipo "direção errada" nas quais é comum tomar o efeito pela causa (relação invertida) (CERDARBLOM; PAULSEN, 2005). O Quadro 3 destaca exemplos dos itens e respostas esperadas.

\begin{tabular}{|c|c|c|}
\hline $\mathbf{N}$ & Questão & Esperava-se que ele percebesse que... \\
\hline \multicolumn{3}{|c|}{ Impossíveis } \\
\hline 1 & Quando eu bebo muita água, eu fico com sede. & $\begin{array}{l}\text {... havia uma inversão na frase e o correto deveria ser } \\
\text { quando eu fico com sede, eu bebo muita água. }\end{array}$ \\
\hline 2 & $\begin{array}{l}\text { Está chovendo, porque vou levar meu guarda- } \\
\text { chuva. }\end{array}$ & $\begin{array}{l}\text {... havia uma inversão na frase e o correto deveria ser vou } \\
\text { levar meu guarda-chuva, porque está chovendo. }\end{array}$ \\
\hline 3 & $\begin{array}{l}\text { O time de João fez mais gols na partida, porque } \\
\text { ganhou o jogo. }\end{array}$ & $\begin{array}{l}\text {... havia uma inversão na frase e o correto deveria ser o } \\
\text { time de João ganhou o jogo, porque fez mais gols na } \\
\text { partida. }\end{array}$ \\
\hline \multicolumn{3}{|c|}{ Possíveis } \\
\hline 4 & $\begin{array}{l}\text { O passarinho conseguiu fugir, } \\
\text { esqueceram aberta a porta da gaiola. }\end{array}$ & $\begin{array}{l}\text {.. o fato era possível de ocorrer nesta ordem, ou seja, a } \\
\text { sequência causa/efeito estava correta. }\end{array}$ \\
\hline 5 & $\begin{array}{l}\text { Meu pai mandou acender as luzes, porque estava } \\
\text { muito escuro. }\end{array}$ & $\begin{array}{l}\text {... o fato era possível de ocorrer nesta ordem, ou seja, a } \\
\text { sequência causa/efeito estava correta. }\end{array}$ \\
\hline
\end{tabular}

Quadro 3 - Itens da variável com Inversão Causal e respostas esperadas Fonte: Elaborado pelos autores (2016).

- Variável Problemas com Inversão Temporal - IT:

$\mathrm{Na}$ elaboração dos itens considerou-se "[...] o fator tempo na atribuição de valor verdade a uma afirmação e na validação [...]” (MACHADO; CUNHA, 2005, p. 73). Em cada um dos itens impossíveis há incompatibilidade entre os tempos verbais e/ou advérbios na sequência dos fatos. Observe-se o Quadro 4, os itens e respostas esperadas:

\begin{tabular}{|c|c|c|}
\hline $\mathbf{N}$ & Questão & ava-se que ele percebesse que era... \\
\hline \multicolumn{3}{|c|}{ Impossíveis } \\
\hline 1 & $\begin{array}{l}\text { Vou convidar meus amigos para virem na minha festa de } \\
\text { aniversário, na semana passada. }\end{array}$ & $\begin{array}{l}\text {... impossível convidar alguém para participar } \\
\text { de um evento que já havia ocorrido. }\end{array}$ \\
\hline 2 & $\begin{array}{l}\text { O homem que construiu minha casa fez primeiro o } \\
\text { telhado, depois, levantou as paredes. }\end{array}$ & $\begin{array}{l}\text {... impossível construir uma casa nessa } \\
\text { sequência temporal. }\end{array}$ \\
\hline 3 & $\begin{array}{l}\text { Marcelo está na creche. Ele adora olhar as fotos da } \\
\text { viagem que fez quando era adolescente. }\end{array}$ & $\begin{array}{l}\text {... impossível ver fotos de uma etapa da vida } \\
\text { que ainda não havia ocorrido. }\end{array}$ \\
\hline \multicolumn{3}{|c|}{ Possíveis } \\
\hline 4 & $\begin{array}{l}\text { No domingo, eu fui para a cama às } 7 \text { horas da noite, } \\
\text { porque tinha de levantar cedo na segunda-feira. }\end{array}$ & $\begin{array}{l}\text {... possível que os fatos ocorressem nessa } \\
\text { ordem. }\end{array}$ \\
\hline 5 & $\begin{array}{l}\text { A irmã de Ana tem } 8 \text { anos. Ela vai fazer } 9 \text { anos no ano } \\
\text { que vem. }\end{array}$ & $\begin{array}{l}\text {... possível que os fatos ocorressem nessa } \\
\text { ordem. }\end{array}$ \\
\hline
\end{tabular}


- Variável Problemas Gerais - G: foram incluídos aqui diferentes tipos de violação lógica não incluídos nas anteriores. O Quadro 5 apresenta os itens e respostas para essa variável.

\begin{tabular}{|c|c|c|}
\hline $\mathbf{N}$ & Questão & ava-se que o participante percebesse que era... \\
\hline \multicolumn{3}{|c|}{ Impossíveis } \\
\hline 1 & $\begin{array}{l}\text { Lúcia foi descendo da árvore até chegar ao alto } \ldots \text { in } \\
\text { dela. }\end{array}$ & apossível descer da árvore e chegar no alto dela. \\
\hline 2 & João é filho único e tem dois irmãos. & $\begin{array}{l}\text { npossível ser filho único e ter irmãos ao mesmo } \\
\text { o. }\end{array}$ \\
\hline 3 & $\begin{array}{l}\text { O pai de Alfredo abriu o guarda-chuva, porque } \ldots \text { in } \\
\text { não estava mais chovendo. }\end{array}$ & $\begin{array}{l}\text { npossível abrir o guarda-chuva depois que a chuva } \\
\text { de cair. }\end{array}$ \\
\hline \multicolumn{3}{|c|}{ Possíveis } \\
\hline 4 & $\begin{array}{l}\text { Flavia saiu primeiro que sua irmã para ir para a escola, } \\
\text { mas chegou depois. }\end{array}$ & ... possível de ocorrência dos eventos descritos. \\
\hline 5 & $\begin{array}{l}\text { O cachorro de Marcelo é muito bravo, mas nunca } \\
\text { mordeu ninguém. }\end{array}$ & possível de ocorrência dos eventos descritos. \\
\hline
\end{tabular}

Quadro 5 - Itens da variável Gerais e respostas esperadas Fonte: Elaborado pelos autores (2016).

\subsection{Procedimento}

$\mathrm{Na}$ aplicação do instrumento, buscou-se obter a resposta ao item e também a justificativa dos participantes, utilizando-se o inquérito enquanto realizavam individualmente a atividade proposta. $\mathrm{O}$ tempo médio de cada participante na aplicação foi de uma hora.

\section{Resultados}

Duas etapas compuseram a análise dos dados: uma análise quantitativa e outra qualitativa. A apresentação dos resultados foi organizada da seguinte forma:

- Análise quantitativa: resultados estatísticos do desempenho dos participantes por questões.

- Análise qualitativa: justificativas dadas pelos participantes.

\subsection{Análise quantitativa}

\subsubsection{Resultado dos testes estatísticos}

Testes estatísticos foram realizados para: confirmar a normalidade da amostra; verificar a significância da diferença entre os grupos; e testar a hipótese do estudo. Utilizou-se o programa estatístico SPSS for Windows 20.0 (Statistical Package for the Social Sciences. Para a entrada de dados no software foram utilizados os números de acertos produzidos pelos participantes dos dois grupos ( $\mathrm{F}$ e f), considerando-se a resposta e a justificativa ao item 
corretas. O teste $t$-Student foi escolhido para verificação da significância da diferença entre os resultados e a prova Kolmogorov-Smirnov foi realizada para verificar se a distribuição de cada amostra era normal. Quando o resultado apontou para uma distribuição não normal, foi realizado também o teste de Mann-Whitney.

\subsubsection{Normalidade da amostra e os resultados dos testes de hipótese}

Para testar a diferença entre os grupos, formulou-se a seguinte hipótese nula para confrontar a hipótese em estudo:

$H_{0:}$ Não há diferença no desempenho entre os participantes dos dois grupos para as variáveis do estudo.

A Tabela 1 descreve os resultados de cada teste estatístico aplicado em cada variável para os diferentes grupos de participantes. Nos testes estatísticos, os itens das variáveis em estudo apresentaram os valores esperados, isto é, o desempenho, ou seja, a média de acertos dos participantes do grupo $\mathrm{F}$ foi melhor do que do grupo f. Em sua maioria, os problemascontrole apresentaram distribuição não normal pelo teste de normalidade. Então, foi aplicado o teste de Mann-Whitney, indicando p $>0,05$, reafirmando que, de fato, não houve diferença significativa nos resultados de acertos nos dois grupos de participantes. No entanto, observouse que os problemas-controle que envolviam lógica Gerais-possíveis apresentaram resultados não esperados, pois se comportaram como uma amostra normal, indicando que eles não serviram como problemas-controle.

Em resumo, de acordo com os testes estatísticos, pode-se afirmar que:

- Os participantes classificados como fortes (F) no desempenho em atividades matemáticas (de aritmética) alcançaram mais acertos nos problemas matemáticos (de aritmética) do que aqueles considerados com desempenho fraco (f);

- Os participantes classificados como fortes (F) no desempenho em atividades matemáticas (de aritmética) apresentaram melhor desempenho nos problemas que envolvem lógica do que aqueles considerados com desempenho fraco (f);

- Os problemas que envolvem lógica Gerais do tipo possível não funcionaram como problemas-controle para esta variável, indicando que houve dificuldades nos dois grupos para sua resolução. Quanto a isso, cabe destacar que Nunes e Bryant (2015) têm alertado para a pouca preocupação no ensino de probabilidade, o que tem gerado dificuldade nos alunos em compreender o mundo, “chegando à conclusões lógicas a partir de pressupostos e relações" (p. 5). 
Tabela 1 - Apresentação dos resultados dos testes estatísticos

\begin{tabular}{|c|c|c|c|c|c|c|c|c|c|c|c|c|c|}
\hline \multirow{2}{*}{ Variáveis } & \multirow{2}{*}{ Tipo } & \multirow{2}{*}{$\begin{array}{l}\text { Classi- } \\
\text { ficação }\end{array}$} & \multirow{2}{*}{$\mathbf{N}$} & \multicolumn{2}{|c|}{$\begin{array}{c}\text { Kolmogorov- } \\
\text { Smirnov* }\end{array}$} & \multicolumn{4}{|c|}{ t Student** } & \multicolumn{4}{|c|}{ Mann-Whitney *** } \\
\hline & & & & Z & $\begin{array}{c}\mathrm{p} \\
\text { (bicaudal) }\end{array}$ & Média & $\begin{array}{l}\text { desvio } \\
\text { padrão }\end{array}$ & $\mathrm{t}$ & $\mathrm{p}$ & $\begin{array}{l}\text { Ordem } \\
\text { média }\end{array}$ & $\begin{array}{c}\text { soma } \\
\text { ordens }\end{array}$ & $\mathrm{U}$ & $\mathrm{p}$ \\
\hline sem & \multirow{6}{*}{ 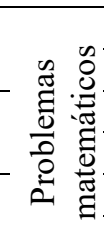 } & $\mathrm{f}$ & 13 & 0,62 & 0,84 & 5,15 & 3,05 & \multirow{2}{*}{3,93} & \multirow{2}{*}{0,00} & & & & \\
\hline número & & $\mathrm{F}$ & 13 & 0,69 & 0,72 & 9,00 & 1,78 & & & & & & \\
\hline \multirow{2}{*}{$\begin{array}{l}\text { sem } \\
\text { solução }\end{array}$} & & $\mathrm{F}$ & 13 & 1,03 & 0,24 & 3,92 & 1,80 & \multirow{2}{*}{2,11} & \multirow{2}{*}{0,02} & & & & \\
\hline & & $\mathrm{F}$ & 13 & 0,88 & 0,43 & 5,69 & 2,43 & & & & & & \\
\hline \multirow{2}{*}{$\begin{array}{l}\text { com } \\
\text { solução }\end{array}$} & & $\mathrm{F}$ & 13 & 0,76 & 0,61 & & & & & 10,92 & 142,00 & \multirow{2}{*}{51,00} & \multirow{2}{*}{0,09} \\
\hline & & $\mathrm{F}$ & 13 & 1,56 & 0,02 & & & & & 16,08 & 209,00 & & \\
\hline \multirow{2}{*}{$\begin{array}{l}\text { Inv. causal } \\
\text { impossíveis }\end{array}$} & \multirow{12}{*}{ 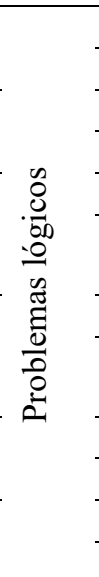 } & $\mathrm{F}$ & 13 & 0,94 & 0,34 & 2,54 & 1,45 & \multirow{2}{*}{5,70} & \multirow{2}{*}{0,00} & & & & \\
\hline & & $\mathrm{F}$ & 13 & 0,88 & 0,42 & 6,08 & 1,71 & & & & & & \\
\hline \multirow{2}{*}{$\begin{array}{l}\text { Inv. causal } \\
\text { possíveis }\end{array}$} & & $\mathrm{F}$ & 13 & 0,93 & 0,35 & & & & & 12,23 & 159,00 & \multirow{2}{*}{68,00} & \multirow{2}{*}{0,42} \\
\hline & & $\mathrm{F}$ & 13 & 1,46 & 0,03 & & & & & 14,77 & 192,00 & & \\
\hline \multirow{2}{*}{$\begin{array}{l}\text { Inv. } \\
\text { temporal } \\
\text { impossíveis }\end{array}$} & & $\mathrm{F}$ & 13 & 1,05 & 0,22 & 4,92 & 1,44 & \multirow[b]{2}{*}{2,34} & \multirow[b]{2}{*}{0,01} & & & & \\
\hline & & $\mathrm{F}$ & 13 & 0,99 & 0,28 & 6,08 & 1,04 & & & & & & \\
\hline \multirow{2}{*}{$\begin{array}{l}\text { Inv. } \\
\text { temporal } \\
\text { possíveis }\end{array}$} & & $\mathrm{F}$ & 13 & 1,19 & 0,12 & & & & & 10,96 & 142,50 & \multirow[b]{2}{*}{51,50} & \multirow[b]{2}{*}{0,09} \\
\hline & & $\mathrm{F}$ & 13 & 1,92 & 0,00 & & & & & 16,04 & 208,50 & & \\
\hline \multirow{2}{*}{$\begin{array}{l}\text { Gerais - } \\
\text { impossíveis }\end{array}$} & & $\mathrm{F}$ & 13 & 0,97 & 0,30 & 6,38 & 1,56 & \multirow{2}{*}{2,17} & \multirow{2}{*}{0,00} & & & & \\
\hline & & $\mathrm{F}$ & 13 & 1,25 & 0,09 & 7,48 & 0,88 & & & & & & \\
\hline Gerais - & & $\mathrm{F}$ & 13 & 0,83 & 0,50 & 1,38 & 0,37 & & & & & & \\
\hline possíveis & & $\mathrm{F}$ & 13 & 0,71 & 0,69 & 2,00 & 1,63 & & 0,15 & & & & \\
\hline
\end{tabular}

Fonte: Elaborada pelos autores (2017).

Nota: * Teste Kolmogorov-Smirnov para verificar se a distribuição é normal.

** Teste t-Student para verificar a diferença significativa entre os dois grupos com amostras normais.

*** Teste Mann-Whitney para comprovar a diferença entre os dois grupos com amostras não normais.

\subsubsection{Análise do desempenho dos dois grupos: $F$ e f}

A Tabela 2 apresenta os resultados globais dos desempenhos dos participantes dos dois grupos ( $\mathrm{F}$ e f) verificados nas duas variáveis que envolviam raciocínio matemático.

Tabela 2 - Resultados globais verificados nas variáveis que envolviam raciocínio matemático

\begin{tabular}{lccccccc}
\hline \multicolumn{1}{c}{$\begin{array}{c}\text { Questões } \\
\text { matemáticas }\end{array}$} & $\begin{array}{c}\text { Classi- } \\
\text { ficação }\end{array}$ & $\begin{array}{c}\text { Parti- } \\
\text { cipantes }\end{array}$ & $\begin{array}{c}\text { Total de } \\
\text { respostas }\end{array}$ & Acertos & $\%$ & Média & Amplitude \\
\hline sem número & $\mathrm{F}$ & 13 & 156 & 117 & 74,36 & 9,75 & $6-12$ \\
\cline { 2 - 8 }$(\mathrm{t}=12)$ & $\mathrm{f}$ & 13 & 156 & 67 & 43,59 & 5,58 & $2-9$ \\
\hline sem solução & $\mathrm{F}$ & 13 & 91 & 63 & 80,22 & 9,00 & $7-9$ \\
\cline { 2 - 8 }$(\mathrm{t}=7)$ & $\mathrm{f}$ & 13 & 91 & 44 & 35,16 & 6,29 & $4-9$ \\
\hline com solução & $\mathrm{F}$ & 13 & 65 & 54 & 83,08 & 10,80 & $7-13$ \\
$(\mathrm{t}=5)$ & $\mathrm{f}$ & 13 & 65 & 39 & 60,00 & 7,8 & $4-11$ \\
\hline
\end{tabular}

Fonte: Elaborada pelos autores (2017).

A média de acertos indica valores mais baixos para o grupo $f$ em relação ao grupo $F$, para todas as variáveis. A amplitude também indica que houve maior dispersão entre acertos e erros no grupo f em relação ao grupo F. Apesar de alguns dos participantes não se comportarem como o esperado para sua classificação, isso não foi suficiente para contaminar os resultados. 
Dando prosseguimento à análise, a Tabela 3 descreve os resultados globais dos desempenhos dos participantes dos dois grupos (F e f) nos problemas lógicos.

Tabela 3 - Resultados globais verificados nas variáveis que envolviam raciocínio lógico

\begin{tabular}{|c|c|c|c|c|c|c|c|c|c|}
\hline Variável & Tipo & $\mathrm{N}$ & $\begin{array}{c}\text { Classi } \\
\text { ficação }\end{array}$ & $\begin{array}{c}\text { Partici- } \\
\text { pantes }\end{array}$ & $\begin{array}{c}\text { Total } \\
\text { esperado } \\
\text { respostas } \\
\text { corretas }\end{array}$ & $\begin{array}{c}\text { Total } \\
\text { Acertos }\end{array}$ & $\begin{array}{c}\% \\
\text { acertos }\end{array}$ & $\begin{array}{c}\text { Média } \\
\text { acertos/ } \\
\text { questão }\end{array}$ & $\begin{array}{c}\text { Amplitude } \\
\text { acertos }\end{array}$ \\
\hline \multirow{4}{*}{$\begin{array}{c}\text { Inversão } \\
\text { Causal } \\
\text { - IC }\end{array}$} & \multirow{2}{*}{ I } & \multirow{2}{*}{8} & $\mathrm{~F}$ & 13 & \multirow{2}{*}{104} & 79 & 75,96 & 9,88 & $7-12$ \\
\hline & & & $\mathrm{f}$ & 13 & & 33 & 31,73 & 4,13 & $0-11$ \\
\hline & \multirow{2}{*}{$\mathrm{P}$} & \multirow{2}{*}{4} & $\mathrm{~F}$ & 13 & \multirow{2}{*}{52} & 45 & 86,54 & 11,25 & $9-13$ \\
\hline & & & $\mathrm{f}$ & 13 & & 42 & 80,77 & 10,50 & $10-11$ \\
\hline \multirow{4}{*}{$\begin{array}{c}\text { Inversão } \\
\text { Temporal } \\
\text { - IT }\end{array}$} & \multirow{2}{*}{ I } & \multirow{2}{*}{8} & $\mathrm{~F}$ & 13 & \multirow{2}{*}{104} & 86 & 82,70 & 11,50 & $9-13$ \\
\hline & & & $\mathrm{f}$ & 13 & & 77 & 74,04 & 9,38 & $7-13$ \\
\hline & \multirow{2}{*}{$\mathrm{P}$} & \multirow{2}{*}{4} & $\mathrm{~F}$ & 13 & \multirow{2}{*}{52} & 51 & 98,08 & 12,75 & $12-13$ \\
\hline & & & $\mathrm{f}$ & 13 & & 46 & 88,46 & 11,75 & $11-13$ \\
\hline \multirow{4}{*}{$\begin{array}{c}\text { Gerais } \\
\text { - G }\end{array}$} & \multirow{2}{*}{ I } & \multirow{2}{*}{8} & $\mathrm{~F}$ & 13 & \multirow{2}{*}{104} & 97 & 93,27 & 12,13 & $11-13$ \\
\hline & & & $\mathrm{f}$ & 13 & & 83 & 79,81 & 10,38 & $8-12$ \\
\hline & \multirow{2}{*}{$\mathrm{P}$} & \multirow{2}{*}{4} & $\mathrm{~F}$ & 13 & \multirow{2}{*}{52} & 26 & 50,00 & 6,50 & $5-7$ \\
\hline & & & $\mathrm{f}$ & 13 & & 18 & 34,62 & 4,50 & $3-7$ \\
\hline
\end{tabular}

Apesar de os desempenhos dos participantes diferirem em cada uma das variáveis para mais ou para menos, observou-se que houve diferença maior nos acertos para os participantes do grupo $\mathrm{F}$ em detrimento do grupo $\mathrm{f}$ em todas elas. A amplitude destaca que houve maior diferença de acertos no grupo $\mathrm{f}$.

Os resultados em ambos os conjuntos de problemas (matemáticos e que envolviam lógica) destacaram o melhor desempenho dos participantes classificados como $\mathrm{F}$ em comparação com os do grupo f, o que corrobora os resultados dos testes estatísticos.

\subsection{Análise qualitativa}

\subsubsection{Agrupamento das justificativas}

Os dados coletados para essa análise foram obtidos a partir das justificativas dadas por cada participante, as quais, independentemente de sua resposta estar ou não correta, não apontavam a violação lógica ou a possibilidade de resolução matemática. As categorias construídas para agrupar as justificativas para análise estão descritas a seguir.

\subsubsection{Agrupamentos para os problemas matemáticos}

CIN - Controle Inadequado pela presença/ausência de Números: respostas que indicam que a presença ou a ausência de números controlou de forma incorreta/indevida o raciocínio em 
direção à solução do problema. Isso se verificou em cinco situações diferentes, sendo elas:

a) Realizar incorretamente uma operação aritmética, independentemente de ela contribuir ou não para a solução

b) “Armar" incorretamente o algoritmo

c) Interpretar incorretamente/não reconhecer zero como um número

d) Inserir números para exemplificar, para explicar ou para completar o raciocínio

e) Efetuar operações com números disponíveis no problema, ainda que:

e.1. desnecessário;

e.2. não justificado

f) Declarar-se confuso pela falta de números, ainda que estes fossem desnecessários para a tarefa pedida.

CIT - Controle Incorreto por Termo ou Expressão: forte controle verbal de algum termo ou expressão do enunciado sobre a resposta.

FVI - Formulação Verbal Imprecisa: identificou corretamente o erro, porém a formulação verbal de sua resposta foi incompleta ou imprecisa.

RI - Regras Implícitas: utiliza palavras ou expressões presentes no enunciado para realização do algoritmo ou operação para responder ao problema.

As categorias apresentadas até aqui, informavam alguma estratégia em busca da solução e, por isso, elas foram denominadas de estratégia. Outras categorias não produziram material capaz de informar um raciocínio executado e estão descritas a seguir:

Inq - Inquérito: justificativas que parecem ter sido emitidas basicamente em função de um inquérito inadequado.

NJ - Não Justificar ou não responder: o participante não apresentou alguma justificativa seja por omissão, seja por não querer explicar sua resposta.

JI - Justificativa Incompreensivel: o conteúdo verbal que constitui a justificativa da resposta não permite qualquer tipo de classificação. 


\subsubsection{Agrupamentos utilizados para os problemas que envolvem lógica}

Há um bloco de questões cujas respostas desconsideram a violação incorreta ou material que torna o problema incorreto, no caso dos problemas impossíveis, ou a inexistência de violação, no caso dos possíveis. Para esse bloco, as categorias estão listadas a seguir:

CEF - Corrigir Estrutura da Frase: ao invés de acusar/descrever a afirmação, apresenta uma formulação correta que afirma/julga corrigir a frase.

CP - Conhecimento Prévio: vale-se de conhecimento do cotidiano (correto ou incorreto e não na possibilidade/ impossibilidade lógica da afirmação).

CRI - Controle por Regra Inadequada: a justificativa envolve a afirmação de relações incorretas ou circunstanciais.

CIT - Controle Incorreto por Termo ou Expressão: a justificativa evidencia forte controle verbal de algum termo ou expressão do enunciado sobre a resposta.

IC - Inserir Condições: o participante insere condições desnecessárias ou não autorizadas para contornar a dificuldade causada pela violação lógica, ao invés de corrigi-la.

Há outro grupo de categorias que não se encaixam na definição geral acima e estão elencadas abaixo:

FVI - Formulação Verbal Imprecisa: a justificativa sugere que o participante identificou corretamente o erro, porém a formulação verbal de sua resposta foi incompleta ou imprecisa.

Inc - Incoerência: a justificativa é contraditória em relação à resposta (pode/não pode), isto é, o participante afirma que a frase representa um fato que PODE ocorrer, porém a justificativa remete a razões pelas quais o fato NÃO PODERIA ocorrer, e vice-versa.

Como no item anterior, também aqui optou-se por separar as categorias que indicavam alguma estratégia daquelas que não informavam um raciocínio executado, sendo estas: Inq (Inquérito), JI (Justificativa Incompreensível ou Inadequada) e NJ (Não justificar ou não responder). 


\subsubsection{Classificação das justificativas dadas pelos participantes}

\subsubsection{Problemas Matemáticos Sem Número}

Nesta variável, destacou-se uma dificuldade comum: resolver um problema matemático que não contem números ou nos quais os números não eram insuficientes para sua resolução, observado em respostas, como:

Não dá pra resolver, porque não tem números (Inquérito de aluno 4 (f), 2016).

Essa eu não consigo, porque não tem número (Inquérito de aluno 25 (f), 2016).

Isso pode indicar o pouco domínio matemático sobre uma situação-problema, visto que o erro não foi originado na dificuldade em trabalhar com os números, mas na dificuldade de elaborar um procedimento para resolver o item.

Excluindo-se as categorias Inq, NJ e JI que somaram mais de 58,5\% das justificativas e utilizando-se as categorias denominadas estratégia, observou-se que a categoria CIN (controle inadequado por presença/ausência de números) foi a que apresentou maior frequência.

Esse dado sugere que a pouca frequência/eficiência do desenvolvimento dessa atividade em sala de aula, dando-se preferência às atividades repetitivas de exercícios escritos que incluem operações, tem contribuído para a dificuldade na aprendizagem de resolução de problemas e mais, tem gerado uma compreensão de que resolver problemas matemáticos é somente possível com a execução de operações (CÂMARA, 2009; MEDEIROS, 2001; NUNES; CARRAHER; SCHLIEMANN, 2011).

Ressalta-se que Skinner (1969) estabelece uma clara distinção entre dois momentos do processo: resolução de problemas refere-se a todas as respostas preliminares na tentativa de resolver ou em direção à solução do problema; já solução de problemas refere-se à resposta que resolve o problema. Essa distinção foi mantida no presente trabalho.

De acordo com Nunes, Carraher e Schleimann (2011, p. 87) “aprendemos na escola não somente a resolver operações aritméticas, mas também atitudes e valores relativos ao que é apropriado em matemática. A matemática aprendemos implicitamente, é uma atividade que se pratica por escrito". A inclusão de números (CIN-d) foi o que mais controlou o raciocínio dos participantes $(27,9 \%)$. 


\subsubsection{Problemas Matemáticos Com/Sem Solução}

Também aqui as categorias Inq, NJ e JI agregaram 52\% das respostas.

Analisando somente aquelas categorias que dizem respeito a uma tentativa de raciocinar matematicamente, foi a presença/ausência de números (CIN) que agrupou a maioria das justificativas. Para as questões do tipo Sem Solução a inserção desnecessária de operações foi a estratégia mais utilizada, com frequência em CIN-e1 de 62,5\%, apesar de essa ação produzir resultados inexplicáveis, como no exemplo do problema:

Paulo tem 3 carrinhos e 4 aviões.

Quantos soldadinhos ele tem?

Grande parte dos participantes recorreu à soma dos valores presentes no enunciado $(3+4=7)$, justificando sua resposta com a inclusão de uma informação não permitida/fornecida pela questão, com respostas do tipo:

Ele tem sete. Um soldadinho para cada avião e cada carro (Inquérito de aluno 5 (F), 2016).

Isto indica que realizar operações é uma resposta muito forte no repertório dos participantes ao se defrontarem com situações-problema de Matemática.

Observando os resultados apresentados nas duas variáveis de problemas matemáticos, verificou-se que o controle que o número exerceu na solução das questões foi muito forte. A hipótese aqui aventada é a de que a simples existência dele no enunciado fez com que muitos organizassem seu pensamento para formular estratégias e justificativas relacionadas à execução de operações, ainda que estas não fossem necessárias para a solução dos mesmos e eles não conseguissem explicar sua ação. Com relação às frequências das justificativas dos grupos (F e f), assim como nos problemas Sem Número, ambos buscaram responder aos itens utilizando justificativas incorretas similares (ainda que com maior frequência para o grupo f).

Nessa variável, o que mais se destacou foi a dificuldade dos participantes em admitir que um problema matemático não tivesse solução. Além disso, ficou evidente que muitos dos participantes executaram as operações mecanicamente. Mais uma vez aqui, parece que a concepção de Matemática escolar tem atuado como um forte controlador da estratégia utilizada pelos participantes.

Em seu estudo, Câmara (2009) verificou que os estudantes sabem efetuar cálculos, sua dificuldade está nas atividades de resolução de problema. Já Brito (2006, p. 20) destaca que a resolução de problemas "não se trata de um tipo exclusivo de aprendizagem, mas sim da reformulação e ampliação dos conceitos e princípios já aprendidos e que nesta nova situação são combinados e reagrupados". Isto indica que ou a concepção sobre Matemática tem forte 
influência na resolução de um item matemático, ou a falta de compreensão lógica do item tem dirigido o aluno a buscar estratégias sem sentido. Corroborando isto, a autora acrescenta que a “compreensão do problema surge a partir da leitura da situação proposta que precisa apresentar lógica e coerência para o aprendiz" (CÂMARA, 2009, p. 34).

Contudo, é difícil detectar se a dificuldade apresentada pelos participantes estaria mais relacionada às ações didáticas ou dificuldades com a Matemática ou, ainda, a dificuldade com questões que envolvem lógica. De acordo com Nunes e Bryant (1997, p. 28) essa linha divisória é difícil de ser percebida, pois a

maioria das pessoas aceitaria que na aprendizagem da matemática há princípios lógicos e há invenções culturais, e que as crianças têm que dominar ambos os aspectos. A linha divisória real entre os dois é frequentemente bastante difícil de estabelecer, e a extensão na qual as dificuldades das crianças são lógicas ou resultam da necessidade de aprender convenções específicas frequentemente não fíca completamente clara.

Questionou-se, então, se o fato de os participantes não terem desenvolvido o raciocínio lógico verbal poderia ser um agravante na resolução de problemas matemáticos de aritmética. Partiu-se para a análise das justificativas dadas para os problemas que envolviam lógica.

\subsubsection{Problemas que envolviam a Lógica}

As categorias não estratégia somaram valores próximos dos 50\%, o que demonstra que houve dificuldades para solucionarem e justificarem suas estratégias. As categorias que não demonstraram um raciocínio identificado como lógico foram eliminadas para a análise das categorias que indicavam estratégias para resolução do item. Observa-se os resultados na Tabela 4:

Tabela 4 - Distribuição das justificativas de estratégia dos participantes para os problemas que envolvem lógica

\begin{tabular}{cccccccccc}
\hline Variável & Freq. / \% & CEF & IC & CP & Inc & CRI & CIT & FVI & $\boldsymbol{\Sigma}$ \\
\hline Inversão Temporal & Freq. Parcial & 6 & 1 & 1 & 1 & 0 & 2 & 7 & 18 \\
\hline Gerais & Freq. Parcial & 22 & 9 & 11 & 1 & 39 & 0 & 7 & 89 \\
\hline Inversão Causal & Freq. Parcial & 116 & 14 & 18 & 0 & 0 & 17 & 2 & 167 \\
\hline & Freq. Total & 144 & 24 & 30 & 2 & 39 & 19 & 16 & 274 \\
\cline { 2 - 8 } & \% Total & 52,6 & 8,8 & 10,9 & 14,2 & 6,9 & 100,0 \\
\cline { 2 - 8 } & \multicolumn{2}{c}{ Fonte: Elaborado pelos autores (2017). } & & & &
\end{tabular}

A variável Inversão Temporal foi a que causou menor dificuldade nos participantes dos dois grupos, gerando melhor distribuição de frequências entre as categorias, não se verificando, portanto, destaque de frequência no agrupamento de nenhuma delas. 
Com relação à variável Gerais, os problemas do tipo impossíveis não causaram dificuldades. De outro lado, os problemas-controle (tipo possível) provocaram muitos erros, computando mais de $80 \%$ das dificuldades encontradas pelos participantes nessa variável. A categoria que indica o controle por regras inadequadas (CRI) foi a que agrupou a maior parte das justificativas, 44\% delas, sobretudo no tipo possível. Houve dificuldade entre os participantes em aceitar a probabilidade de ocorrência/não ocorrência de eventos a partir do enunciado proposto, para eles, o fato de haver uma determinada causa certamente implicaria a ocorrência do efeito, como, por exemplo, no item:

O cachorro de Marcelo é muito bravo, mas nunca mordeu ninguém.

Os participantes consideravam que pelo fato de o cachorro ser bravo, ele deveria ter mordido alguém. Algo semelhante foi encontrado por Tineli (2006), que observou que o desempenho dos participantes era melhor quando as premissas continham, em seu texto, conteúdos desconhecidos e era pior quando as premissas apresentavam conteúdos conhecidos. Isto porque, segundo a autora, as crianças ficavam menos influenciadas por suas experiências anteriores. Algo interessante verifica-se aqui. De fato, nossos conhecimentos e experiências estão baseados na realidade e, desse ponto de vista, faz pouco sentido imaginar que se prescinda de nossas experiências, sensações e conhecimentos para estabelecer julgamentos. Deste ponto de vista, o que está expresso aqui é a questão da diferença entre lógica material e lógica formal.

Já os problemas da variável Inversão Causal foram os maiores causadores de erros. A estratégia mais utilizada nesse tipo de problema, e que computou quase $70 \%$ das respostas, foi a de corrigir a estrutura da frase (CEF). Essas respostas indicam que o participante identificou erro na frase, mas não sua inversão lógica. O inquérito colaborou com essa análise, pois se utilizou dele para identificar a possibilidade de que o participante tivesse identificado a inversão, mas não tivesse conseguido verbaliza-la. Entretanto, suas respostas às indagações da pesquisadora confirmaram que havia ausência de compreensão desta inversão, preocupandose o participante em afirmar que a frase deveria ser corrigida, pois foi escrita errada. Verificou-se que a influência incorreta do conteúdo do enunciado no raciocínio do participante foi mais forte do que a inversão lógica apresentada. Em algumas questões, esse controle foi tão forte que não permitiu que sequer um deles acertasse a correção da frase, embora tenha identificado algum erro. Observou-se que as justificativas dadas pelos dois grupos, embora com frequências diferentes, são similares na estratégia utilizada, assim como ocorreu nos problemas matemáticos. 
Observando os resultados encontrados nos dois blocos de problemas (matemáticos e os que envolviam a lógica), é possível verificar que, em grande parte dos erros encontrados, a dificuldade está nos participantes não compreenderem o conteúdo apresentado, seja pelo controle exercido pelo conteúdo das frases, no caso dos problemas que envolvem lógica verbal, seja pelo controle exercido pelo número nos problemas matemáticos.

\section{Discussão}

Os resultados encontrados neste estudo sugerem que há correlação entre o raciocínio lógico (argumentação) e o raciocínio matemático (em atividades de aritmética), uma vez que o desempenho dos grupos indicou que aqueles que obtiveram maior número de acertos nos problemas matemáticos os obtiveram igualmente nos problemas que envolvem lógica, o mesmo ocorrendo para o grupo que obteve baixo desempenho em atividades matemáticas e em atividades que envolviam lógica, comprovados estatisticamente.

Esse resultado corrobora os estudos de Brito, Fini e Garcia (1994), que concluíram, a partir de seu trabalho, que apesar da importância da formulação verbal do problema matemático para a identificação das informações apresentadas no enunciado, é preciso que o indivíduo consiga identificar o fundamental e o acessório, através das relações mútuas entre esses elementos. Para os autores, a compreensão do problema só se dá quando “[...] o sujeito percebe que os elementos fazem sentido em termos matemáticos [...]” (p. 44). Coincide também com os dados do trabalho de Nunes et al. (2007) que identificaram, em um estudo longitudinal, a relação causal entre lógica e desenvolvimento matemático, indicando que ela é forte preditora como fator para a realização matemática das crianças.

Com relação ao raciocínio utilizado pelos participantes, o controle do número (tanto pela presença, quanto pela ausência dele) foi primordial na tentativa de solucionar a questão nos problemas matemáticos. Quanto a isso, Luna e Marinotti (2012, p. 49) relataram que “[...] parece ser suficiente para eles a existência de uma frase com números para que eles suponham a existência de uma operação, bastando que se efetue uma conta”.

Já nos problemas que envolviam raciocínio lógico, as categorias que indicavam falta de percepção da inversão lógica (ou da falta dela) foram as que obtiveram maiores frequências nos erros. Em ambos os conjuntos, portanto, a dificuldade em solucionar problemas foi a maior geradora de erro nos participantes. Apesar de as variáveis que envolvem lógica controlarem diferentes estratégias nos participantes, os problemas 
provocadores de dificuldade indicaram forte controle incorreto pelo conteúdo da frase mais do que pela inversão presente nela.

Percebeu-se, portanto, que a compreensão da frase "poderá não ser usada, deixando o informante de determinar conclusões corretas e recorrer a falácias, quando influenciado pelo conteúdo das premissas, por suas crenças ou por não possuir habilidades que ela requer" (RODRIGUES; DIAS; ROAZZI, 2002, p. 118). A partir dos resultados encontrados, observase que as dificuldades estão relacionadas à falta de compreensão de relações lógicas, assim como foi verificado na análise dos problemas matemáticos, em que a dificuldade em executar as tarefas matemáticas propiciou a utilização de estratégias não permitidas pelo item.

Ressalta-se que, neste estudo, a seleção intencional e controlada dos participantes foi necessária para melhor avaliar a hipótese construída, mas deve servir de alerta ao leitor para a impossibilidade de generalizações.

\section{Considerações finais}

A importância dos resultados deste estudo vão além da confirmação da correlação entre lógica e Matemática, pois se observou que as dificuldades de aprendizagem muitas vezes podem não estar relacionadas propriamente ao conteúdo ensinado, mas à forma como ele está sendo ensinado.

Câmara (2009, p. 14, ênfases do autor) alerta que "[...] o importante, para o aluno, é "visualizar" os números apresentados no enunciado e identificar a "boa operação" a ser realizada, geralmente pela associação a palavras-chave, tais como ganhar para a adição ou perder para a subtração”. Zunino (1995) também destaca essa prática e conclui que “[...] centrar o aprendizado da matemática na aquisição de mecanismos conduz não somente a obstaculizar a utilização dos esquemas conceituais que as crianças constroem, como também a desvirtuar o conhecimento matemático em si” (Zunino, 1995, p. 189). Esses mecanismos utilizados pelo professor como estimulador da aprendizagem, por vezes, têm levado o aprendiz a fazer relações incorretas, dificultando sua aprendizagem da disciplina, como destacam Nunes e Bryant:

[...] não é suficiente aprender procedimentos; é necessário transformar esses procedimentos em ferramentas de pensamento [...] É a compreensão das situações que dá sentido a procedimentos matemáticos gerais [...] Se os sistemas de representação e procedimentos para manipular estes símbolos irão influenciar o nosso pensamento, eles devem ter sentido (NUNES; BRYANT, 1997, p. 31). 
Diante dos resultados encontrados nessa pesquisa, indica-se que a análise qualitativa seja inserida como um importante instrumento na avaliação que os professores realizam sobre o desempenho dos alunos em Matemática e para elaboração de estratégias de superação das dificuldades deles e planejamento de sua ação pedagógica, enfatizando a observação feita por Krutetskii (1976, p. 38) de que "[...] um baixo nível do componente lógico-verbal de pensamento determina dificuldades para a compreensão da matemática”.

Sugere-se que novos estudos sobre o tema sejam elaborados, com o intuito de oferecer subsídios para as discussões/formação de professores e, também, para se repensar o ensino e a avaliação dessa disciplina na Educação Básica.

\section{Agradecimentos}

Agradecimentos vão à escola que possibilitou e cedeu seu espaço para a realização dessa pesquisa e ao Conselho Nacional de Desenvolvimento Científico e Tecnológico - CNPq que financiou esse estudo.

\section{Referências}

ANDRÉ, M.E.D.A. Etnografia da Prática Escolar. 18. ed. Campinas: Papirus, 2013.

BRITO, M. R. F. Alguns aspectos teóricos e conceituais da solução de problemas matemáticos. In: BRITO, M. R. F. (Org.). Solução de problemas e a matemática escolar. Campinas: Ed. Alínea, 2006. p. 13-53.

BRITO, M. R. F.; FINI, L. D. T.; GARCIA, V. J. N. Um estudo exploratório sobre as relações entre o raciocínio verbal e o raciocínio matemático. Pro-posições, Campinas, v. 5, n. 1 (13), p. 37-44, mar. 1994. Disponível em: https://www.fe.unicamp.br/pf-fe/publicacao/ 1796/13_artigo_britomrf_etal.pdf. Acesso em: 23 out. 2017.

CÂMARA, M. Nossos alunos não sabem somar? O que (não) dizem os resultados da avaliação em larga escala de Pernambuco. In: SEMINÁRIO INTERNACIONAL DE PESQUISA EM EDUCAÇÃO MATEMÁTICA, 4., 2009, Taguatinga. Anais... Taguatinga: SBEM, 2009.

CERDABLOM, J.; PAULSEN, D. Critical reasoning. 6. ed. Califórnia: Wadsworth, 2005.

KRAMM, D. L. Resolução de problemas: possíveis relações entre raciocínio lógico e desempenho em matemática. 2014. 398f. Dissertação (Mestrado em Educação: Psicologia da Educação) Pontifícia Universidade Católica de São Paulo, São Paulo, 2014.

KRUTETSKII, W. The Psychology of Mathematical Abilities in School Children. Chicago: The University of Chicago Press, 1976.

LUNA, S. V. de. O falso conflito entre tendências metodológicas. Cadernos de Pesquisa, São Paulo, n. 66, p. 70-74, ago. 1988.

LUNA, S. V.; MARINOTTI, M. Raciocínio lógico e aprendizagem de matemática: alguns elementos 
para a análise de relações entre estes repertórios. In: CARMO, J. S.; RIBEIRO, M. J. F. X. (Org.). Contribuições da análise do comportamento para a prática educativa. Santo André: ESETec, 2012. p. 181-205.

MACHADO, N.; CUNHA, M. O. Lógica e linguagem cotidiana: verdade, coerência, comunicação, argumentação. Belo Horizonte: Autêntica, 2005.

MEDEIROS, K. M. de. O contrato didático e a resolução de problemas matemáticos em sala de aula, SBEM Educação Matemática em revista, São Paulo, v. 8, n. 9/10, p. 34-39, 2001.

MEIRA, L. L., DIAS, M. G. \& SPINILLO, A. G. Raciocínio lógico-matemático: aprendizagem e desenvolvimento. Temas em Psicologia. Ribeirão Preto, v. 1, n. 1, p. 113-127, 1993

NUNES, T.; BRYANT, P. Crianças fazendo matemática. Porto Alegre: Artes Médicas, 1997.

NUNES, T.; BRYANT, P. Uma visão da matemática para o ensino multidisciplinar. Conferência realizada para a CAPES Brasília: Coordenação de Aperfeiçoamento de Pessoal de Nível Superior, 2015.

NUNES, T. et al. The relative importance of two different mathematical abilities to mathematical achievement. British Journal of Educational Psychology, London, v. 82, n. 1, p. 136-156, mar. 2012.

NUNES, T.; CARRAHER, D.; SCHLIEMAN; A. Na vida dez, na escola zero. 16. ed. São Paulo: Cortez, 2011.

NUNES, T. et al. The contribution of logical reasoning to the learning of mathematics in primary school. British Journal of Developmental Psychology, London, v. 25, n.1, p. 147-166, mar. 2007.

OLIVEIRA, P. A. O raciocínio matemático à luz de uma epistemologia. Educação e Matemática, Lisboa, n. 100, p 3-9, 2008.

RODRIGUES, A. A., DIAS, M. G. B. B.; ROAZZI, A. Raciocínio lógico na compreensão de texto. Estudos de Psicologia. v. 1, n. 7, p. 117-113, 2002. Disponível em: http://www.scielo.br/ pdf/pepsic/v7n1/10959.pdf. Acesso em: 26 mai. 2014.

RUSSEL, S. Mathematical reasoning in the elementary grades. In: STIFF, L. V.; CURCIO, F. R. (Ed.). Developing mathematical reasoning in grades K-12. Reston: NCTM, 1999. p. 1-12.

SÃO PAULO. Secretaria da Educação. SARESP. Relatório Pedagógico Saresp 2013: Língua Portuguesa e Matemática. São Paulo: SEE, FDE, 2014. Disponível em:

http://file.fde.sp.gov.br/saresp/saresp2013/Arquivos/SARESP\%202013_Relat\%C3\%B3rio\%20Pedag \%C3\%B3gico\%202\%C2\%BA_3\%C2\%BA\%20EF.pdf. Acesso em: 20 jan. 2015.

SKINNER, B. F. Contingencies of Reinforcement: A Theoretical Analysis. Englewood Cliffs: Prentice-Hall, 1969.

TINELI, C. Desenvolvimento do raciocínio lógico e educação: um estudo com crianças de 4 a 6 anos. 2006. 108f. Dissertação (Mestrado em Educação: Psicologia da Educação) - Pontifícia Universidade Católica de São Paulo, São Paulo, 2006.

ZUNINO, D. L. A matemática na escola: aqui e agora. 2. ed. Porto Alegre: Artmed, 1995. 